so that the strong expression of opinion in favour of the muzzling regulations (in conjunction with the disingenuousness of the argument of their opponents) is easily understood.

From a survey of the known behaviour of animals affected with rabies, and in accordance with the measures customarily adopted in dealing with infection among animals, where as in the present case it is not desirable to interfere with their free movement from place to place, Mr. Chaplin declared a number of counties as infected, taking areas around to provide sufficient margin against conveyance of contagion.

It is this wise and carefully-designed attempt to stamp out the disease, which the Standard, alone in the Press, has attacked in the most unmeasured language. Having no "case" from the scientific and medical stand-point, the editor through his leader-writers abuses his opponent's attorney (if Mr. Chaplin will forgive the simile). The Conservatives in Kent are positively called upon by the leading daily paper of their party to vote against their own Government, and why? Because they are asked to help stamp out rabies; and at what cost? it may be asked. None save that of the hire of a muzzle.

This is where the difficulty of our kind of Government arises. Because a solitary voice in the Press objects to a sanitary measure, which has nothing whatever to do with politics, ill-feeling is to be aroused among the voters. It is, however, satisfactory to add that possibly no such attempt on the part of any journal has ever met with such a chilling reception from the rest of its contemporaries those who have not refrained from observations on the matter having only mentioned it to utterly condemn it.

A sanitary question, to our mind, becomes a question of moral right or wrong when the means proposed for its solution involve nothing beyond a little reasonable trouble, and it is this view of the matter 'which we fancy finally crystallizes out in the form of what is called public opinion. After the process of the actual experience of the last five years, public opinion is evidently set in the direction of preventing hydrophobia by muzzling. It is of course impossibie that $\mathrm{Mr}$. Chaplin should yield to this, the first abusive attack that has been made upon him in his official capacity, but certainly if anything should support him, it is the cognizance of the unworthiness of the opposition which the Standard has fomented against his action in the service of the community.

We should wish in conclusion to direct attention to certain obvious deductions which can justly be drawn from the history of this matter, and other events connected with the subject of rabies.

Both the prevention and the cure of this horrible zymotic malady are the outcome of close scientific experimental work. It was reserved for M. Pasteur to make clear and harmonize the various stages (always obscure and apparently contradictory at first) of our knowledge by the immense progress he inaugurated and carried out in the study of infection.

It is M. Pasteur who himself has pointed out better than anyone how the disease can be prevented from attacking man or animals, and he is the first who has shown in the slightest degree how it can be prevented from developing in the system after it has gained access to the body.
The nineteenth century, however, affords no shelter to the man of science to discover benefits for his fellowmen, for although the progress of knowledge has fortunately destroyed the Inquisition, yet society tolerates the existence of the anti-vivisectionist agitation, which not only scatters broadcast the foulest and falsest aspersions on such a man's life and character, but in its most recent development violently opposes the advance of hygiene.

\section{POLYTECHNICS FOR LONDON}

W HETHER or not the London County Council comes to the wise decision to utilize the provisions of the new Technical Instruction Act, it is probable that for the most part Londoners will have to look for intermediate and higher technical instruction to other agencies than rate-aided schools, at all events in the immediate future. In these matters London is in an exceptional position as the capital of the Empire. In the first place, it is the natural home of the Normal Schools of Science and Art which form part of the machinery of the Science and Art Department. And, besides this, it is the centre of greatest activity of the organization of the City and Guilds Institute, whose three model Colleges are all situated within the metropolitan area.

The proportion, however, of the inhabitants of London whose education is affected by these higher institutions is necessarily small. The Government schools are imperial rather than local, and their situation is chosen regardless of the industrial needs of London. The Central Institution of the City and Guilds likewise belies its name by its situation at South Kensington. The other two schools of the City and Guilds, at Finsbury and Kennington, have a direct and most important relation to surrounding industries, and keep high the standard of what teaching in applied science and ari ought to be. But teaching of this high order is very expensive, though the fees charged may be low, and of recent years a newer and more popular movement has sprung up, aiming at a lower standard of instruction carried on at less cost, and adapted, so far as practicable, to the benefit of the mass of working men.

The best type of such institutions in London is the so-called "Polytechnic" in Regent Street. The basis of the organization is the Young Men's Christian Institute started some years ago by Mr. Quintin Hogg. Round this nucleus he has gradually built up an institution in which evening classes, recreation, and gymnastics have all a part. Under his guidance the Institute has grown to great dimensions, and a number of very largely-attended classes of all kinds are now conducted in the building which for many years was occupied by the "Polytechnic" of the diving-bell and Prof. Pepper. Many of the classes are in general and commercial subjects, but there are science and art classes in connection with South Kensington, technological classes in connection with the City and Guilds Institute, and trade and practical classes in various industries and handicrafts. The greater part are held in the evening, but there are also day classes; and day schools for boys and girls are attached to the institution.

It will be seen that this experiment in technical educa- 
tion differs very materially in plan from that of such an institution as Finsbury College. The educational side of the Polytechnic does not form an organized school course so much as a set of classes among which a student may choose, and the standard aimed at is not so high. But there is this obvious advantage in taking the Polytechnic as a model for similar institutions that the instruction, so far as it goes, is far less costly than at Finsbury, being largely subsidized by science and art grants.

The example of the Polytechnic has been recently followed, with a certain amount of success, at the People's Palace in Mile End, where the Drapers' Company have devoted the funds which they have withdrawn from the City and Guilds Institute to building and endowing a school somewhat on the Polytechnic lines.

While these institutions have been developing, the Charity Commissioners have been engaged in pursuance of Mr. Bryce's Act of 1883 in framing a scheme for the application of the funds of the City parochial charities for the benefit of the working classes of greater London. The Commissioners came early to the determination to devote a large proportion of the proceeds of the charities to some educational purpose, and decided further that the main direction of the educational institutions thus established should be technical and industrial.

It is not our purpose to enter at all into the questions that have been raised as to the mode of division of the endowment between secular and ecclesiastical purposes, or the wisdom of tying up the greater part of the disposable funds in perpetuity. There are plenty of keen , bservers who will make their views felt on these questions; and indeed many champions of other schemes, such as the promotion of open spaces, are already in the field. But we must regard the main object to which the funds will be devoted as practically decided. The Charity Commissioners gave notice of it in their last Report, and little exception seemed then to be taken to the project. Since then large sums of money have been raised by local subscriptions on the faith of the proposal. It is too late now to advocate the application of the main part of the fund to any other object than education, and those who are agitating for such a change are, in our opinion, wasting their powder and shot.

But while the public is easily induced to join in a general outcry which, if it has any justification, certainly comes far too late, it is quite possible that, unless vigilant care is exercised, the final scheme may come into force without those alterations and improvements in detail which seem individually of small importance, but may make all the difference between a good and a bad scheme of technical education for London. The funds handled are far larger than those authorized to be raised for the whole of Wales under the new Intermediate Education Act. It behoves all friends of education to take care that these large endowments are used aright.

Let us glance, then, at the main outline of the scheme so far as it relates to technical education. The Commissioners were instructed under the Act to make provision for the "poorer classes." Consequently any technical schools established or aided under the scheme must aim directly at the benefit of the workman rather than that of the manager.

The Commissioners propose to devote large capital grants to the erection of technical and recreative institutes in various parts of London, somewhat on the model of the Regent Street Polytechnic, and to give a permanent endowment to these institutes, as well as to the Polytechnic and the People's Palace already in existence. Each institute is to be governed under a scheme, devised by the Charity Commission, and is to be subject to the general control of a Central Governing Body of Trustees.

The objects of the institutes are threefold. They are to be social centres, where concerts and entertainments may be given, and where outside clubs and working men's societies may have an opportunity of meeting; they are to include young men's and young women's institutes for social and recreative purposes, open to "young persons" between the ages of sixteen and twenty-five; and lastly, they are to provide for the educational wants of the working classes in the neighbourhood. Libraries, museums, swimming-baths, and gymnasia will form part of the equipment of most of these institutions.

It is with the educational work of these "Polytechnics" that we are here most directly concerned. But their educational and social sides must be very closely linked together, and the success of the classes will largely depend on the success of the institute as a whole. Entrance to the clubs may, under the scheme, be made contingent on entrance to the classes, as is now the case at the People's Palace, though such a course seems to us to be unwise. In any case we must not pass over the social side of the institutes without a word. The Young Men's Institute at the Polytechnic has been a great success, but it has been a growth of time, and it has grown round the nucleus of the Y.M.C.A. The social Institute at the People's Palace has sprung suddenly into existence, without the pre-existing nucleus; it is admitted to have been a failure, and is now suppressed. Can the lesson be mistaken? Doubtless the Charity Commissioners are alive to the difficulty. Their detailed regulations for the management of an institute, of which the draft has been published, are, in the main, carefully drawn. But those who hope that the scheme will result in the growth of a number of Palaces of Delight which will delight Mr. Walter Besant's heart will be doomed to disappointment. There will be no "People's Palaces"-only "Young People's Institutes." The present People's Palace will be constrained to confine its membership in future to persons between the ages of sixteen and twenty-five. Why this limitation? We see with pleasure that the Goldsmiths' Company, who are founding an institute at New Cross on somewhat the same model as those proposed by the scheme, have struck out the upper limit. There are far too many of these restrictions in the scheme. For example, smoking and dancing are (the latter with certain specified exceptions) forbidden. Surely details such as these can be left to the by-laws of the several institutes. Here, again, the Goldsmiths' Company have shown themselves in advance of the Charity Commission.

We have a similar criticism to make on the whole of the educational scheme. There is too little guidance in matters of principle, too much restriction in matters of detail.

Perhaps the most important thing to ensure is that the Central Governing Body shall be a strong body, exercising effective supervision over the teaching of the various 
institutes. Its official name ("Trustees of the City Parochial Charities") is unfortunate; it has too much of a flavour of Mr. Bumble's "porochial" office. It would require an Act of Parliament to change the name, so the best thing to do is to let it be forgotten. The Central Governing Body (for so let us call it) is to be representative of the Crown, the City Corporation, the County Council, the higher Colleges and University of London, the Ecclesiastical Commissioners (temporarily), and the Governing Bodies of the Bishopsgate and Cripplegate Foundations. No one can forecast the action of such a hybrid body until we know the actual men who are to be nominated. A very efficient educational body might be elected as proposed, and on the other hand it mightn't. It is to be hoped that one of the blots on the constitution of the Board-the absence of working-men representativeswill be partly corrected by the inclusion of some workingmen leaders among the five Crown nominees. But it is impossible to resist the conviction that the suggested constitution-suitable enough to the time when the Act was passed and London had no organized system of local government-has far too little of the popular element, and that it would be far better to put the whole management of the scheme in the hands of the County Council, or a joint committee of the County Council and School Board.

Supposing that the Central Body is all that could be wished, the next thing to ensure is the satisfactory composition of the governing bodies of the various institutes, and their organic connection with the Central Body. It is essential that the schemes shall be so arranged that the educational programme of all the institutes shall pass through the hands of competent experts, and the educational work shall be adequately supervised, inspected, and revised, from time to time. The Charity Commissioners propose two methods of attaining this result. They give three nominations on each governing Board to the Central Governing Body, and these threemembers may be experts, though of this there is no guarantee. Further, the secretary of each institute is required to send to the secretary of the Central Governing Body a complete list of proposed classes a week before each term. This is presumably intended to give a power of suggestion, if not revision, to the Central Body, but what is the use of suggestions a week before term? What is wanted is a central committee of well-known experts to advise the Central Governing Body on educational matters. The committee should be small-say three scientific and three artistic representatives. They should be paid for their services, and should be in touch with the science and art divisions of every institute.

There is nothing in the scheme to prevent the appointment of such a Committee, though it would be well if some distinct suggestion of the kind were made. In any case it is a matter to be borne in mind and pressed when the time comes, for it may make all the difference in the world to the future of technical education in London. Let us be frank about the matter. How many men are likely in any given district to be on the governing body of the local institute who know the difference between good teaching and bad? And yet no scheme, however admirably drawn, will produce a good technical school, unless it is worked by such men. On the other hand, with a first-rate governing body we have little fear. Payment by results will lose most of its terrors if those in power know the difference between the incompetence which cannot earn grants, and the independence which prefers real teaching to cram. And we may add that it is only by associating with the governing body members engaged in local industries that the practical character of the trade classes can be assured.

So much for the machinery. We must next say a word about the character of the instruction to be aimed at in the institutions. It is to be mainly technical, and hence must be adapted to the special needs of each locality. It is by this time a truism to say that this adaptation will not be brought about by allowing a set of science and art teachers to take the line of least resistance through the South Kensington Directory to the goal of the maximum of grant. A lady is reported to have lately obtained a silver medal for agriculture at a London institution which the Charity Commissioners are proposing to endow. Is this adaptation to local needs and industries?

We wish sincerely that those responsible for the whole scheme had been able to arrange for exceptional treatment of the new linstitutes in the matter of the apportionment of the Government grant now paid on results. No better opportunity is likely to present itself for an experiment in basing grant on efficient inspection rather than on examination. But what chance is there of such a proposal when our Government departments responsible for public education are cut $\mathrm{u} p$ into air-tight compartments without connection among themselves? The Charity Commission, the Education Department, and the Science and Art Department still form a great circumlocution office, and until this is altered abuses will continue, which it is nobody's business to remedy. Our great hope, therefore, depends on the choice of the principals, teachers, secretaries, inspectors, and governing bodies, who will make or mar the institutes through which, for many years, Londoners will derive their technical instruction. Let them be enlightened men, with broad views and sympathies, who know their business, or at least know their limitations, and all may be well. But if not, it were better that the whole scheme were put in the fire.

What, again, is to be the scope of the instruction? Is it to be mainly confined to the level of "elementary" science and "second-grade" art? Or are there to be advanced classes in more specialized subjects? Provision is made for such classes in the scheme if they can be arranged without trenching on the endowment. The Commismissioners are probably afraid of misapplying funds intended for the poor to the benefit of the middle classes. There is justice in their objection, but such instruction can never be made self-supporting, and it is most important that it should be included in the programme of the institutes, if only to keep the standard high throughout. Here is then an opportunity for the City and Guilds Institute. Let it relieve itself of the charge of its examinations, which may now be transferred on equitable terms to the Science and Art Department under the provisions of the Technical Instruction Act, and let it also transfer to the Government the Central Institution, the geographical situation of which marks it out plainly as an adjunct rather than a rival to the Normal School, and let it apply the energy thus liberated in establishing in every "Poly- 
technic" a higher department, providing for the more specialized wants of each locality. This will be a work which no body is so well fitted to undertake as the great Institute which has been a pioneer in higher technical instruction. Such, it appears to us, is the true solution of the question of the relations between the Charity Commissioners' scheme and the City and Guilds of London.

One word of caution in conclusion. The new institutes should be allowed to grow, and not be started on too ambitious a scale at first. Local wants change, and the institutes should develop in harmony with their changes. This is the lesson of the old Mechanics' Institutes and Athenæums. The lesson is repeated in the newer experiments of Mr. Hogg's Polytechnic, and the People's Palace. We do not want to begin with erecting huge shells of bricks and mortar, hoping that life will somehow come into them after a time. The life first, then the buildings, to grow as it expands and deepens-that surely is the law of nature. "Several architectural white elephants" is the dismal but suggestive forecast of a writer in the Charity Organization Review, on the supposition that this law is violated. If these warnings are neglected, the promoters of the movement will be merely courting failure, however good their intentions may be. And they will have failed because "they were not poets enough to understand that life develops from within."

\section{ASSA YING.}

Text-book of Assaying. By C. Beringer and J. J. Beringer. (London: Griffin and Co., I889.)

THIS text-book marks an important departure in the literature of assaying. The authors abandon the dreary details of traditionary methods, and attempt with success to rationalize the art of the assayer, rather than to follow the usual course of reproducing "dry" assay methods and elaborate classifications of processes the interest of which is only historical. Assaying is here treated, in a broad sense, as the determination, by analytical methods, of components of ores and of intermediate or finished metallurgical products. Such compounds may be either of value in themselves, or important from being valuable or injurious in the operations of smelting, or in adapting the metals for use.

The methods of the authors, and the measure of success which they have attained, may be fairly judged by their treatment of copper, ead, and iron. Copper ores and furnace materials are still sold in the English market by the "Cornish" assay. This antiquated method of assaying has really no claim to retention, now that more trustworthy methods are well known, and the authors give it but little prominence. They, however, repeat the fallacious argument of its apologists by stating that "it gives the purchaser an idea of the quantity and quality of the metal that can be got by smelting." The Cornish assay does not deserve even this modified approval, as the results it affords neither represent the actual amount of copper contained in the ore, nor the proportion of metal which can be produced by smelting, and several expert assayers, working on portions of the same samples, will obtain results which vary in the most erratic way. Fortunately for those who may be guided by this text-book, its authors proceed to describe assaying processes which are really well calculated to give trustworthy indications as to the quantity and quality of metal obtainable from ores. These are to be found in well proved "wet" methods of determining actual copper contained in ores as well as the components that interfere with the extraction and the quality of the metal. In describing these methods, ample information is given for the guidance of the smelter under the varying conditions of the metal's occurrence. While passing shortly over the Cornish assay, the authors judiciously omit such clumsy "wet" methods of assay as the direct titration by cyanide of potassium, which is retained in some recent books of standing, although it has been abandoned by most skilful assayers. On the other hand, titration by cyanide of potassium after separation of the copper from interfering metals, and the assay by electrolysis, leave little to be desired in rapidity and accuracy, and to these due prominence is given. Failing reasonable manipulative skill, no assay can be accurate, and the expertness demanded by those who conduct the "dry" or Cornish assay is not more easily acquired than is the analytical skill needed for better "wet" methods. In an assay method giving accurately the amount of metal actually present in the ore, the metallurgist has a sure basis for calculation, the results of which can be brought under the control of his experience as to the losses of metal in operations on a large scale. The results of the Cornish assay, with all its inherent uncertainty, have equally to be judged in the light of the smelter's experience as to what the final "out-turn " will be. In lead, again, the dry assay is usually treated in books on assaying with much elaboration, which is no longer useful, if it ever was. It gives results that indicate neither the actual amount of metal contained in the ore, nor the amount which will be produced by smelting, and like the Cornish assay for copper is most unsatisfactory for guidance in smelting. The wet methods of lead assaying which are described are convenient and trustworthy, while the only practically useful methods of dry lead assay are given in sufficient detail. In the assay of iron ores we find dry methods entirely omitted. The wisdom of this cannot be doubted, for the want of exactitude which is characteristic of the dry assay of copper and lead is still more marked in the dry assay of iron. Processes of wet assay capable of giving prompt and strictly accurate results are available, and these are fully described.

The plan of subordinating or ignoring unsatisfactory methods of assay, while giving prominence to those which have proved to be trustworthy, runs through the treatment of methods of assaying the other metals, as well as estimating the components of ores which are not usually dealt with in books on assaying. Among the latter are silica, the earths, sulphur, arsenic, and phosphorus. These demand study by the metallurgist, to whom, under either the necessity of "fluxing" them away, or of minimizing their interference with the purity of the metals, their ready and accurate determination is a matter of the greatest importance. The details of assaying the precious metals, though hardly sufficient for adoption in the assay of bullion in a mint, are all that is needed in a works.

The authors have clearly not been content to merely record published processes, but in order to add to the completeness of their work have given unpublished 